\title{
CrimRxiv
}

\section{Review 1 of "The politics of being an 'expert': a critical realist auto-ethnography of drug policy advisory panels in the UK"}

Susanne MacGregor ${ }^{1}$

${ }^{1}$ London School of Hygiene and Tropical Medicine

Published on: Nov 02, 2020

DOI: $10.21428 / \mathrm{cb} 6 \mathrm{ab} 371.61 \mathrm{e} 4881 \mathrm{~d}$

License: Creative Commons Attribution 4.0 International License (CC-BY 4.0). 
Vote: Publish as is

[Please explain your vote. If you voted to publish pending minor changes, specify each change, why it is needed, and, possibly, how it should/could be done.]

This is a thought-provoking and original article, which is clearly written and logically structured. Key points are presented succinctly. The article is a reflective discussion of the author's experiences in the role of expert on ACMD committees and advising the parliamentary Health and Social Care Select Committee, with some other reflections based on wider experience added. The argument is located within a specific theoretical approach, a unique combination of critical realism with autoethnography. The observations are placed within a reading of relevant literature on the science-policy relationship.

The author argues that phenomena are not purely the result of a process of social construction but also reflect reality. A key point is about the importance of panels and committees in the process of policy making. It is good to stress this and by implication the importance of the reports which emanate from such panels and committees. Reports exist over time and encapsulate the results of the deliberations of committees and can be used by others within their political activities. They also act as important points of reference over time.

The author adds to the existing literature, which is largely based on analysis of documents and interviews, by referring to evidence from participant observation. The autoethnographic element, in addition to participant observation, is the self-reflection which also forms part of the narrative. He includes a discussion of relations and interactions between physical and social scientists, indicating some of the difficulties each has in understanding the other.

The author mentions some small successes in getting particular recommendations and even specific words included in reports, such as on drug consumption rooms and the concept of decriminalization. These successes should not be underestimated. They do work to move policies forward over time, even though the pace may seem frustratingly slow and involve a huge amount of effort and determination. The author discusses his choice to resign over the issue of political vetting of members of committees. This was a significant act but one senses it also resulted from a process of increasing disillusion and dissatisfaction with his attempt to use committees to bring about change. 
A key question which runs through the article is whether or not it is possible to have a value-free set of evidence. The author also interestingly describes different ways of performing the role of expert in different settings. He identifies the process of selfcensorship adopted by committee members in their attempts to have influence and maintain relations with people in power. This hints at the need to include systems of turnover in the constitution of such groups to allow for periodic refreshment with people willing to challenge the consensus or status quo.

[Please put additional info below, as/if you see fit:]

I used to doubt the value of autoethnography, thinking it too navel-gazing and selfindulgent. This view showed my ignorance. As I have read more about the method, I have become converted to seeing its value. One point about autoethnography, which distinguishes it from participant observation, is the inclusion of more subjective elements. The author does include reflections on his own doubts and uncertainties and responses. In feminist writing, there is more attention paid to emotional responses and there is not much about these in the piece. I suspect there was more irritation and fury at times than is described here - but I may be wrong!

The discussion of who is a suitable expert is interesting. I don't think the word 'trust' appears in the article but this is what is being referred to. There is a large literature on trust in politics. Galbraith is also relevant here as he argued (in The Industrial State) that a person's authority derives from their location in an institution: recognition disappears when an expert ceases to be associated with a key institution (repository of knowledge and information) such as a university or international body.

The selection of a suitable expert also involves their being thought to be sympathetic to the aims of the body doing the selecting. Thus it is not surprising that someone from Release would be rejected by government since Release has throughout its history had as part of its raison d'etre challenging government policy on drugs. The nonacceptance of a representative from Turning Point is more surprising as for some time Turning Point was a voluntary organization seen to have been partially incorporated into government as a service deliverer - however since this was under New Labour perhaps it was more closely identified as an enemy by a Conservative administration. The author's own selection to advise the select committee, as well as reflecting his undoubted qualities, also reflected the interest of key members of that committee in the Portuguese approach of which he was an advocate. 
This issue of political vetting is interesting and calls to mind my own experience of being rejected to serve on ACMD in the early New Labour years. Now this could well have been that there were many better qualified or that at the time there was a move away from appointing too many researchers and a preference for practitioners. However, I recall completing the form, where it asked about one's contributions to other voluntary organisations, and I pondered whether to mention my time as Chair of War on Want. Because I thought it important to be honest, I put this down but this may well have been a red flag to the bull of Jack Straw and other Labour people. (War on Want was identified with groups who might today be viewed within Labour as antiSemitic/ anti-israel, as it had promoted help to the Palestinians). I became involved as Chair to try to clean up the organization after it fell into disrepute - mainly because of what were at the time quite common failings in the voluntary sector regarding financial management. I was quite naïve about the sectarianism within Labour at the time. Be that as it may, I have always wondered if my rejection was partly to do with political vetting. Like involving Release, having anything to do with War on Want would have felt to the Home Office like letting the fox into the hen coop.

We all now see everything through the lens of Covid and much in this article prompts thoughts on the role of experts in the current crisis. The article makes a good contribution to understanding what happens when experts are asked to come to conclusions in a situation of uncertainty - where it is not possible nor appropriate to conduct more research and judgements have to be made. The world of drug policy, like much of criminology, is often in this position.

The author rightly points to the lack of resources for ACMD to do its work properly. More could be written on the history of ACMD. The timidity of members and chairs, commented on in this article, is to some extent the result of the intimidation and bludgeoning it faced following the Nutt era. Both David Nutt and Griffith Edwards were leading and independent Chairs but interpreted the role differently. The role of civil servants has similarly changed over time, especially in recent years with increasing outsourcing of advice. The quality of the secretaries to committees is rightly mentioned as a key influence on the process of deliberation and construction of final reports.

The article mentions the lack of involvement of people with lived experience of drugs on committees. Scotland has attempted to involve such groups more closely with its different system of consultation. Selecting a few to represent drug users is always problematic as it is in attempts to involve service users or the community - what does 
representation mean? This discussion also links into recent attempts by some research groups (with little success I think) to encourage drug researchers to admit to their own drug use, either present or former. Of course, a key role for social researchers has been to be the voice of drug users via ethnography, for example.

A key distinction is made between natural scientists and social scientists - this is an ongoing issue. History would help here too in pointing out how these disciplines have themselves changed over time, partly reflecting the increasing stress on quantitative methods in both. Clinical addiction practitioners too have complained about the dominance of lab based or academic research, as do public health professionals and practitioners today in pointing to the dominance of epidemiology and modelling in discussions of policies on coronavirus. Social science is in a similar position today when so called behavioural scientists are taken to represent the whole of social science. Overall, this indicates the general preference for quantitative rather than qualitative research. There remains a challenge for qualitative researchers to find ways to get their findings across to policy makers and to encourage greater respect for their methods.

The above comments simply indicate how thought provoking this article is and why it merits publication. 